\title{
Los Colegios de San Ignacio y San Francisco Javier de Querétaro. Secularización educativa y conflictos espaciales con la parroquia de Santiago (1825-1841)
}

\author{
The Colleges of San Ignacio and San Francisco Javier. \\ Educational secularization and space conflicts with the \\ parish of Santiago (1825-1841)
}

\section{Maribel Miró Flaquer ${ }^{1}$}

\section{Resumen}

Desde la mirada de la disciplina histórica y sin perder de vista los cambios espaciales del conjunto arquitectónico, el presente texto tiene por objetivo abordar una etapa de la vida de los Colegios de San Ignacio y San Francisco Javier de Querétaro que hasta ahora permanecía en el olvido. Nos referimos a los cuarenta años posteriores a la guerra de Independencia, cuando los entonces Reales Colegios pasaron a estar bajo la jurisdicción de los gobiernos estatales o departamentales, dependiendo del tipo de República en turno. Los primeros planes educativos que se estructuraron desde la capital del país, impactaron en la vida de los Colegios al incorporarlos a una nueva realidad resultado de la transición de la sociedad novohispana a una ordenada bajo parámetros distintos. De manera lenta y gradual, el proceso de secularización fue avanzando y el espíritu corporativo de los Colegios fue debilitándose ante una cada vez mayor interferencia de un Estado en construcción, y el cual, a través de los sucesivos gobiernos, nacionales y locales, intervino no sólo en los asuntos académicos y administrativos, sino que se vio obligado a enfrentase con las autoridades eclesiásticas por la ocupación de aquellos espacios construidos que originalmente habían pertenecido al antiguo Colegio de San Ignacio.

Palabras clave: colegios de San Ignacio y San Francisco Javier, conjunto arquitectónico, educación, Querétaro, secularización

\footnotetext{
${ }^{1}$ Universidad Autónoma de Querétaro, México. Correo electrónico: noiamiro@hotmail.com
} 


\section{Abstract}

From the perspective of historical discipline and architecture, this text aims to address a stage in the life of the Colleges of San Ignacio and San Francisco Javier de Querétaro that until now remained forgotten. We refer to the forty years after the War of Independence, when then The Royal Colleges became under the jurisdiction of state or departmental governments, depending on the type of Republic in turn. The first educational plans that were structured from the capital of the country, impacted on the life of the Colleges by incorporating them into a new reality resulting from the transition of the New Spain society to an ordered one under different parameters. Slowly and gradually, the secularization process was progressing and the corporate spirit of the Colleges was weakening in the face of increasing interference from a State under construction, and which, through successive governments, national and local, intervened not only in academic and administrative matters, but was forced to confront the ecclesiastical authorities for the occupation of those constructed spaces that had originally belonged to the former College of San Ignacio.

\section{Keywords: schools of San Ignacio and San Francisco Javier, architectural ensemble, education, Querétaro, secularization}

\section{Introducción}

A la fecha, la historiografía local aborda de manera insuficiente la transformación que experimentó la educación oficial media y superior. Salvo los datos que aportan las obras de Fernando Díaz Ramírez (Díaz, 1971), Álvaro Arreola (Arreola, 2006) y Alejandro Obregón (Obregón, Rincón y Anaya, 1993), o las más recientes aportaciones de Cecilia Landa (Landa, 2014) y José Ignacio Urquiola (Urquiola, 2017) no se cuenta con estudios relativos a los cambios en la política educativa queretana y su relación con los antiguos Colegios de San Ignacio y San Francisco Javier. Poco se sabe acerca de su conformación como Reales Colegios a partir de la expulsión de los jesuitas (1767) y su posterior transformación en Nacionales Colegios (1825) tras la independencia de México. Por otra parte, los Colegios jesuitas, origen remoto de la Universidad Autónoma de Querétaro, nos legaron un edificio histórico de excepcional belleza y valor incalculable, de cuyas características y transformaciones arquitectónicas muy poco se ha escrito.

Respecto al proceso de secularización que constituye el hilo conductor de la presente investigación, resulta pertinente señalar que el término puede ser entendido como "[...] un proceso que tiene lugar en el ámbito social. En una sociedad secularizada la religión, sus reglas morales y canónicas, han perdido el predominio de la conciencia individual y sus valores han dejado de regir la sociedad" (García, 2010: 61). En el plano de la política se 
refiere a la progresiva independencia del poder político respecto al poder eclesiástico, mientras que en el plano educativo nos parece adecuada para el presente artículo la que lo define como "[...] la formación de un sistema general de instrucción pública controlado por la autoridad civil" (Hidalgo, 2002: 253).

Con el propósito de abonar a una mayor claridad en el sentido que en este estudio se le confiere al término secularización y a su relación con el ámbito de la enseñanza, remitimos al lector a lo asentado por Adelina Arredondo y Roberto González (2014: 140-167). Los anteriores se refieren a la secularización como "el proceso hacia la educación laica en México"2, el cual, en la conformación de un sistema educativo nacional, está integrado por cuatro etapas, a saber:

Una primera que se refiere a las reformas implementadas por los Borbones hacia fines del siglo XVIII y principios del XIX, relativa al papel rector del Estado (en este caso de la Corona española) en cuanto a la educación pública. Dichas reformas incluyeron la expulsión de los jesuitas, quienes dependían directamente del Papa, determinando que sus colegios, misiones y bienes pasaran a la Corona. También se ordenó que las diócesis quedaran bajo la dirección del clero secular, de ahí que las órdenes religiosas tuvieran que renunciar a la administración de las parroquias.

Una segunda etapa inicia con la conformación de la República y la Constitución de 1824, misma que estableció la obligación de las instituciones políticas de fomentar la implementación de cada uno de los niveles educativos. Así, los gobiernos estatales se asumieron como garantes de la educación pública y en muchas entidades de la República las instituciones de educación media y superior pasaron a ser administradas por los gobiernos de los estados y no por las congregaciones religiosas ni por las diócesis católicas. Esta etapa se cierra con la creación de la Dirección General de Instrucción Pública, el principio de libertad de enseñanza y el interés por la formación de ciudadanos "con espíritu crítico y racional", durante el gobierno de Valentín Gómez Farías.

Una tercera etapa se refiere a los intentos por uniformar la educación bajo los lineamientos de un sistema político centralizado que se materializa en el decreto de 1843, el cual estableció un Plan General de Estudios obligatorio para toda la República. Si bien se trató de garantizar una educación religiosa (obviamente católica), administrativamente todas las instituciones educativas que habían establecido los poderes locales fueron colocadas bajo el control del gobierno nacional.

La cuarta etapa que corresponde a la erradicación de religión del currículum escolar durante la República Restaurada y la quinta que culmina con la redacción del artículo tercero de la Constitución de 1917, no son materia de este texto. ${ }^{2}$ Por educación laica se entiende aquella que carece de contenido de índole religiosa y que suele ser impartida por el
Estado. 
Retomando nuestro tema de estudio, es de sobra conocido que la Iglesia Católica dominó el panorama educativo de la Nueva España; los colegios del clero regular fueron expandiéndose a lo largo del territorio destacando la labor de los miembros de la Compañía de Jesús. Sin embargo, como ya se señaló, desde las reformas borbónicas se inició un proceso de secularización de la enseñanza en todos sus niveles y fue entonces cuando la Corona Española "[...] reivindicó en el discurso político y en las prácticas educativas el papel rector del Estado sobre la instrucción pública [...]" (Arredondo y González, 2014: 3). Parte de la estrategia de secularización de la Corona fue el decreto de expulsión de los jesuitas de 1767.

En la ciudad de Querétaro funcionaron hasta la expulsión de la orden de todos los dominios españoles, el Colegio de San Ignacio y el Seminario de San Francisco Javier, dedicados a la educación de seglares ${ }^{3}$ en todos los niveles de la enseñanza. El conjunto arquitectónico que albergaba tanto al Colegio como al Seminario, a la salida de la Compañía de Jesús estaba prácticamente terminado; sólo quedaban pendientes obras menores de adecuación. Tras la expulsión de los jesuitas, una Cédula Real de fecha 9 de julio de 1769 , ordenó la organización de juntas encargadas de asignar nuevos destinos a los edificios y demás bienes de la orden. Así se determinó que el Colegio de San Ignacio iba a ser destinado para habitación de los jóvenes que se alojaban en el Seminario de San Francisco Javier, mismo que se utilizaría, temporalmente, para concentrar a la tropa (Medina, 1972: 285). Ahora bien, resulta indispensable poner fin a uno de los paradigmas de la historia de los Colegios: el término "seminario" en el caso particular del de San Francisco Javier, originalmente correspondía al de seminario convictorio, destinado a la residencia de los estudiantes foráneos. Este seminario convictorio o de internos, debe distinguirse de los seminarios clericales o conciliares (O’Neill, 2001: 684), cuya función era la preparación exclusiva de aquellos estudiantes que profesarían el sacerdocio.

Tres años más tarde, el rey Carlos III, en una carta enviada al virrey de la Nueva España Antonio María de Bucareli con fecha 26 de septiembre de 1772, aprobaba lo acordado por la Junta de Aplicaciones y disponía que se continuaran impartiendo las mismas cátedras y subsistiera la escuela de primeras letras (Medina, 1972: 285). El templo (iglesia de San Ignacio) se convertiría en sede de la parroquia de Santiago, ya que se carecía de un edificio propio desde la secularización parroquial, cuando los franciscanos en 1759, se retiraron de la administración de los sacramentos.

Si bien se conservaron las tres partes de la obra de los jesuitas; Templo (que incluía la casa profesa), Colegio de San Ignacio y Seminario de Francisco Javier, al conjunto arquitectónico se le llamó Seminario de San Javier, Colegios de San Ignacio y San Francisco Javier, Nacionales Colegios (en contraposición a su carácter de Reales) o Colegio de San Francisco

\footnotetext{
${ }^{3}$ En el contexto religioso, un seglar o laico es toda aquella persona que pertenece a la religión católica a través del bautismo, pero no al clero.
} 
Javier. Todas estas denominaciones recibieron los Colegios, indistintamente, hasta la creación del Colegio Civil del estado en 1870.

\section{El legado}

Así, al inicio de la época independiente el conjunto estaba integrado por la casa cural que ocupaba parte del edificio que había sido la casa de los sacerdotes jesuitas, el Colegio de San Ignacio y el Colegio Seminario de San Francisco. Esa gran obra iniciada con la adquisición de terrenos en una zona privilegiada del pueblo de Querétaro en 1625, cuya construcción de más de $4500 \mathrm{~m}^{2}$ tardó ciento cuarenta años en concluirse, quedó como mudo testimonio de los afanes de la orden. Gruesos y altos muros de piedra, sólidas bóvedas, aplanados decorados con pintura mural, techos de viguería de madera y decorados al modo barroco en la casa de los sacerdotes o casa profesa, el Colegio de San Ignacio y el Seminario convictorio de San Javier, permanecieron como una unidad hasta ese momento. Sin embargo, a partir de entonces el conjunto se sujetó a una división por edificios, separados por actividades diversas. Siendo que no existió una separación física de los espacios, se entremezclaron actividades parroquiales y académicas. Así quedó el escenario para recibir los cambios que traería consigo la época independiente.

En el plano educativo, a principios del siglo XIX las Cortes de Cádiz habían impulsado el proyecto ilustrado de un plan general para la educación pública que en México se vio interrumpido por la Independencia. "La idea de un sistema de instrucción pública que fuera uniforme, centralizado y que comprendiera tres niveles educativos, [...] se canceló con la primera república federal y cada entidad tomó su propio rumbo" (Arredondo, 2014: 45). Por lo tanto, el proyecto de educación pública elaborado y dirigido desde el centro, tuvo que recorrer un largo camino y enfrentar las resistencias de la Iglesia Católica.

El desarrollo de la instrucción pública dependió de cada entidad de acuerdo con sus propias particularidades y en consonancia con los intereses de las élites locales. Cabe añadir que los cambios a nivel superior no necesariamente implicaron la creación de nuevas instituciones; en algunas entidades siguieron operando los antiguos colegios jesuitas (Ríos, 2014: 8-9).

Las primeras tres décadas de vida independiente de México se caracterizaron por la construcción de un proyecto de nación, donde los enfrentamientos por la imposición de una determinada forma de gobierno, las estrecheces del erario y los conflictos con potencias extranjeras, fueron el pan nuestro de cada día. Sin embargo, pese a la falta de certeza crónica y a la continuidad de prácticas corporativas en colegios y universidades, el impulso a la educación pública se convirtió en una constante en el discurso político decimonónico (Ríos, 2014: 8). 


\section{El estado de Querétaro y los "Nacionales" Colegios}

Corría el año de 1825 cuando el Congreso Constituyente del Estado de Querétaro expidió una orden por medio de la cual facultaba al gobierno de la entidad a tomar todas las medidas que estimara convenientes "[...] para la mejor organización de los Colegios de esta capital" . Poco después, el mismo Congreso habilitó al Cobierno del Estado a fin de que interviniera en la vida de los Colegios "organizándolos política y académicamente conforme a las nuevas constituciones local y federal". (Arreola, 2006: 40-41). Así, la Comisión de Instrucción Pública del Congreso estatal redactó un proyecto de ley sobre educación y enseñanza para la juventud, proponiendo además a los autores que debían estudiarse tanto en materia de religión y moral, como en las de derecho y política 5 .

Dos años más tarde se decretó la creación de una cátedra de Derecho civil, político y canónigo que se establecería en el Colegio a partir del 18 de octubre de 1827 y cuyo sostenimiento correría a cargo de la Tesorería del Estado. Con esa misma fecha, otro decreto ${ }^{6}$ establecía los requisitos para graduarse en Filosofía o Facultad Mayor (Derecho o Teología). Los artículos $4^{\circ}$ al $9^{\circ}$, estipulaban la manera de llevar a cabo los exámenes para obtener los respectivos grados ${ }^{7}$, mientras el artículo $10^{\circ}$ obligaba a los graduados a prestar juramento de defender la Inmaculada Concepción ${ }^{8}$, al tiempo que advertía que ningún funcionario o empleado público del Estado podría tomar posesión sin haber prestado juramento de observar el Acta constitutiva, la Constitución federal y las leyes generales. El $12^{\circ}$ apuntaba que los títulos serían en "lo sustancial" como los de la Universidad de México. Otros artículos establecían los montos a pagar por los estudiantes, salvo los "cursantes pobres" que demostraran un aprovechamiento suficiente. ${ }^{9}$

De tal suerte, a la nueva currícula de los Nacionales Colegios empezaron a introducirse nuevas cátedras como la de Derecho civil, las cuales irían paulatinamente desplazando a aquellas ligadas estrechamente con la religiosidad tradicional como lo era la de Teología. Lo anterior muestra los avances de la secularización, al mismo tiempo que prácticas como la de defensa de la Inmaculada Concepción de la Virgen María, evidenciaban la continuidad de la influencia corporativa y la convicción del Gobierno que aun consideraba su obligación el

\footnotetext{
${ }^{4}$ Biblioteca del Congreso, en adelante BC, Colección de Decretos y órdenes del Cobierno 1824-1825.

${ }^{5}$ Archivo Histórico de Querétaro, en adelante AHQ, Fondo Ejecutivo 1827, "Análisis de la Memoria respectiva del año pasado de 1826", Querétaro, 20 de abril de 1827.

${ }^{6}$ BC, Colección de decretos y órdenes del II Congreso del Congreso Constitucional del estado Libre y Soberano de Querétaro, 1827, 4 de octubre.

${ }^{7}$ BC, Colección de decretos y órdenes del II Congreso del Congreso Constitucional del estado Libre y Soberano de Querétaro, 1928, 26 de enero.

${ }^{8}$ Herencia de los colegios jesuitas era la particular devoción de la Compañía a la Virgen María. Ardientes defensores de la Inmaculada Concepción, tras la fundación de algún colegio o casa el ejercicio de sus ministerios, los jesuitas fundaban congregaciones marianas donde los fieles encontraran la salvación a través de sus servicio y veneración.

${ }_{9}^{9}$ BC, Colección de decretos y órdenes del II Congreso del Congreso Constitucional del estado Libre y Soberano de Querétaro, 1827, 4 de octubre).
} 
promover la educación "[...] para que el hombre se instruya, [no solo] en lo que debe a la sociedad y a sus semejantes, sino también en las sagradas obligaciones de la adorada religión que profesamos $[. . .]^{\prime \prime}{ }^{10}$

Con el propósito de garantizar su sostenimiento, en agosto de 1828 una orden del Congreso asumía que el presupuesto estatal debía considerar cubrir mensualmente el déficit que le reportara el Colegio, indispensable para la instrucción de alumnos y cursantes. ${ }^{11}$ Fue durante ese mismo año cuando Franco Maineraiy, en una carta dirigida al gobernador, ofrecía impartir clases de francés en el Colegio de San Javier de manera gratuita y en aras de abonar al proyecto de ley de instrucción que por penurias del erario no se había podido llevar a cabo (AHQ, Fondo Ejecutivo, 1828, 17 de junio).12 A lo que el ciudadano galo se refería, era a un proyecto presentado por la Comisión de Instrucción Pública del Congreso local y el cual, en opinión de dicha Comisión, podría llevarse a cabo si se le asignaba parte de lo recaudado por concepto de diezmos; cosa que no ocurrió. (Congreso, 1828).

En cuanto a la educación superior, además de las cátedras existentes, la Comisión consideraba indispensable fundar las siguientes: de matemáticas puras, mecánica y geografía, botánica, agricultura, derecho público, economía política y estadística, anatomía y cirugía, y dos de medicina (una sobre fisiología e higiene, y otra sobre patología y terapéutica). Esta última, aseguraba, era prioritaria, a fin de evitar que muchos jóvenes abandonaran el estado para estudiarla. Los avances en el conocimiento racional y científico eran evidentes y resultaba necesaria su incorporación a la educación superior, sin embargo, lo anterior no significaba cuestionar o desplazar los principios de la fe católica.

En resumidas cuentas, el proyecto de ley propiamente dicho determinaba que se estableciera una Junta Inspectora de Instrucción Pública en la capital del estado, la cual debería: "Vigilar el arreglo literario y económico del Colegio de San Javier de esta capital". También tendría la facultad de revisar las normas internas del Colegio y proponer al Congreso las adiciones o reformas convenientes (Congreso:1828).

La preocupación por el mejor funcionamiento de los Colegios bajo la tutela del Gobierno fue a partir de entonces una constante. La Tesorería del Estado reportaba en sus cortes de caja los recursos que se destinaban a su sostenimiento ${ }^{13}$, mientras que el gobernador del estado (José María Diez Marina, 1824-1829) se aseguraba de que el Gobierno tuviera un

\footnotetext{
${ }^{10} \mathrm{AHQ}$, Fondo Ejecutivo 1827, "Análisis de la Memoria respectiva del año pasado de 1826", Querétaro, 20 de abril de 1827.

${ }^{11}$ BC, Colección de decretos y órdenes del II Congreso Constitucional del Estado Libre y Soberano de Querétaro, 1828, 4 de agosto.

${ }^{12} \mathrm{AHQ}$, Fondo Ejecutivo, 1828, caja 3, carta de Francisco Maineraiy al gobernador José María Diez Marina, Querétaro, 17 de junio de 1828.

${ }^{13} \mathrm{AHQ}$, Fondo Ejecutivo, 1829, caja 4, "Tesorería General de Querétaro. Corte de caja respectivo al mes de enero, abril y mayo de 1829".
} 
pie dentro de los gruesos muros donde se resguardaban de las nocivas influencias del mundo exterior, sacerdotes catedráticos y colegiales.

El proyecto de ley sobre instrucción pública, el primero de varios que se expedirían en el estado, nunca se concretó. Sin embargo, el gobernador impulsó la creación de una Junta Protectora de Educación a fin de que procurara la organización de los Colegios y " [...] demás establecimientos de educación de la juventud". ${ }^{14}$

A pesar de la creciente intromisión del Gobierno del Estado en la vida interna de los Colegios, la cual mostraba su intención de secularizar la enseñanza, las cátedras continuaron impartiéndose conforme al modelo jesuita; lo anterior ponía de manifiesto la fuerza de las corporaciones y la tensión entre tradición y modernidad..$^{15}$ Las de latín se dividían en dos niveles. El primero conocido como mínimos y menores, comprendía básicamente la gramática latina y nociones de religión; en el segundo curso, de medianos y mayores, se estudiaba sintaxis, ortografía y prosodia latina; poesía, retórica, oratoria e historia religiosa. Los jóvenes que acreditaban esta primera etapa podían ingresar a las cátedras de Filosofía, con una duración de tres años, que incluían, en términos generales: lógica, metafísica, ética, filosofía, matemáticas, física, cosmogonía y geografía. El latín y la Filosofía constituían las bases necesarias para continuar con estudios superiores como Teología, Jurisprudencia y Medicina. (Díaz, 1974: 12-13).

La década de 1830 iniciaba para los Colegios de San Ignacio y San Francisco Javier, sin registrar mayores cambios. El clero secular administraba los bienes heredados de sus fundadores jesuitas, los cuales, aunados al presupuesto que le otorgaba el Gobierno del Estado, le permitían continuar con las cátedras establecidas, sostener a los alumnos internos y cumplir con las obras pías y celebraciones religiosas.

\section{Entre reformas liberales y repúblicas centrales. El control estatal de los Colegios.}

El gobernador Díez Marina cumplió sus cuatro años y las elecciones de agosto de 1829 le dieron el triunfo a José Rafael Canalizo, uno de los hombres más allegados a Santa Anna. A nivel nacional, el presidente Anastasio Bustamante implementó una política centralista, pero fue depuesto y Santa Anna fue electo presidente en abril de 1833 con Valentín Gómez Farías como vicepresidente.

A finales de 1831, el presidente de la Junta Protectora de los Colegios, Ramón Covarrubias, solicitaba al gobernador las cuentas presentadas por José Manuel de Mendiola (rector

\footnotetext{
${ }^{14} \mathrm{AHQ}$, Fondo Ejecutivo 1829, caja 5, carta del gobernador José María Díez Marina al rector Ignacio Gómez, Querétaro, 12 de abril de 1829 .

${ }^{15}$ Para un acercamiento al término modernidad y su significado en contraposición con el de tradición, véase García: 2011.
} 
de 1815 a 1823) correspondientes al periodo en que había estado a cargo de "los Colegios Nacionales de San Ignacio y San Francisco Javier", así como los documentos probatorios. ${ }^{16}$ A solicitud expresa del gobernador, el ex rector, sensiblemente molesto, respondió:

El día 10 de marzo de 1823 entregué por oficio al Poder Ejecutivo los Colegios Nacionales de San Ignacio y San Francisco Javier de esta capital [...] y entregué con ellos precisamente sus archivos, libros de capitales, obras pías y legajos de cuentas, de fincas y gasto diario de los padres proveedores que le sirvieron desde el año de 1815 que recibí el rectorado, hasta el 23 que me retiré [...] Concluyo que fuertemente me ha sorprendido el oficio de la Junta cuando supone que toda la entrega que hice de los Colegios, fue la llave de la sala rectoral. ${ }^{17}$

A principios de 1832 la situación en los Colegios parecía haber alcanzado un punto crítico. El presidente de la Junta Protectora informaba al gobernador Manuel de Ecala, (junio de 1830 a diciembre de 1832) que había aceptado el nombramiento con la esperanza de contribuir a la recuperación de una institución que "[...] ha producido tan buenos hijos y que ha merecido la consideración de la Universidad de México [...]"; pero en su opinión la situación era tan caótica que no tenía remedio, por lo que solicitaba se le relevara del puesto no sin antes advertir que con mucho pesar había ordenado a su hijo no regresar al Colegio. ${ }^{18}$ Pero los Colegios se negaban a morir, así como el Gobierno del Estado a perder la única institución pública de educación media y superior con la que se contaba. Con fecha 21 de marzo un decreto del Congreso de Estado anunciaba que el déficit anual de los Colegios se cubriría en lo sucesivo con los fondos del estado. ${ }^{19}$ (AHQ, Fondo Ejecutivo, 1832, 21 de marzo).

Como quedó señalado, al establecerse el federalismo en 1824 cada estado siguió su propia política en materia educativa. Respecto a la segunda enseñanza y a la educación superior, los gobiernos independientes apostaron por la fundación de institutos literarios; instituciones modernas de corte liberal controladas y administradas siempre por los gobiernos de los estados, mientras que los colegios, fundamentalmente de corte conservador, siguieron vinculados al clero. Tal era el caso de los Colegios de San Ignacio y San Francisco Javier, los cuales, sin embargo, se encontraban cada vez más a expensas del gobierno estatal.

En el contexto político nacional, el presidente Santa Anna decidió retirarse a su hacienda en Veracruz dejando el Gobierno en manos de Gómez Farías. El anterior, asesorado por José María Luis Mora, impulsó la famosa reforma de 1833 que pretendía secularizar la enseñanza,

\footnotetext{
${ }^{16} \mathrm{AHQ}$, Fondo Ejecutivo 1831, caja 2, carta de Ramón Covarrubias al gobernador Manuel de Ecala, Querétaro, 26 de noviembre de 1831

${ }_{17} \mathrm{AHQ}$, Fondo Ejecutivo 1831, caja 13, carta de José Manuel Mendiola al comisionado de la Junta Protectora de los Colegios, Querétaro, 29 de noviembre de 1831

${ }^{18} \mathrm{AHQ}$, Fondo Ejecutivo 1832, caja 1, carta de Ramón Covarrubias al gobernador Manuel De Ecala, Querétaro, 18 de febrero de 1832.

${ }^{19} \mathrm{AHQ}$, Fondo Ejecutivo 1832, caja 1, decreto del Congresos del Estado, Querétaro, 21 de marzo de 1832
} 
para lo cual se estableció la Dirección de Instrucción Pública y suprimió la Real y Pontificia Universidad de México. Para el gobierno federal resultaba impostergable "formar ciudadanos con espíritu crítico y racional, libres del fundamentalismo religioso [...] el proyecto educativo era prioritario a fin de quitar al clero el dominio de las conciencias [...]” (García, 2010: 69).

En consonancia con el proyecto de secularización de la vida nacional, el presidente Gómez Farías ordenó se diera cumplimiento al decreto del Congreso General mediante el cual se cedían a los estados los edificios que había sido propiedad de los jesuitas. (Dublán y Lozano, 1876: 661). En Querétaro, Lino Ramírez se hizo cargo del Gobierno del Estado a partir de junio de 1833 (hasta a junio de 1834) y expidió una nueva Constitución, muy parecida a la del 1825 pero mucho más radical en todo lo relacionado con la Iglesia. Sin embargo, no contó con tiempo suficiente para reproducir en el estado las reformas a la educación que Gómez Farías y Luis Mora intentaban implementar en la capital. Santa Anna volvió a la Presidencia en abril de 1834 y borró de un plumazo las reformas. En 1835 se estableció en el país un régimen central y en lugar de la Constitución de 1824 se publicaron las Siete Leyes por medio de las cuales los estados pasaron a ser departamentos con gobernadores nombrados por el Supremo Poder Ejecutivo.

A poco de tomar posesión, por tercera ocasión, Agustín Canalizo (junio de 1834 - abril de 1837) emitió un decreto por medio del cual se autorizaba el regreso de todos los individuos que habían sido expulsados del estado por el régimen anterior, el de Lino Ramírez, y ordenaba fueran restituidos en sus empleos. ${ }^{20}$ En consecuencia, el bachiller Manuel de Ochoa se dirigía al gobernador en los siguientes términos:

\section{[...] he vuelto a su capital y espero de la integridad de V. E. tenga la bondad de dar la orden correspondiente para que se me entregue el Colegio de que soy rector y la cátedra de teología moral que me pertenecen legítimamente, de cuyos destinos se me había despojado de hecho y con la mayor injusticia por don Lino Ramírez. ${ }^{21}$}

Manuel de Ochoa regresaba así a su antiguo encargo, pero, a cambio, la administración estatal le solicitaba un informe que incluyera el número de alumnos, las clases, cátedras y facultades que se enseñaban, autores que se leían, así como los "caudales que forman su fondo, con expresión de los capitales corrientes, paralizados y perdidos, réditos que el total debía producir [...]". 22

Las solicitudes de información tanto de corte administrativo como académico se convirtieron en una constante y en 1835 el rector de los Nacionales Colegios de San Ignacio y

\footnotetext{
${ }^{20} \mathrm{AHQ}$, Fondo Ejecutivo 1834, caja 3, decreto del gobernador Agustín Canalizo, Querétaro, 24 de junio de 1834.

${ }^{21} \mathrm{AHQ}$, Fondo Ejecutivo 1834, caja 1, carta de Manuel de Ochoa al gobernador Agustín Canalizo, Querétaro, 24 de junio de 1834.

${ }^{22} \mathrm{AHQ}$, Fondo Ejecutivo 1834, caja 3, solicitud del gobernador Agustín Canalizo al rector Manuel de Ochoa, Querétaro, 24 de marzo de 1834
} 
San Francisco Javier, informaba al gobernador que para ese año los teólogos lo eran sólo moralistas y estudiaban el prontuario de Teología compuesto por el reverendo padre fray Francisco Lárraga. Los filósofos cursan el $2^{\circ}$ año y el autor del texto era el "esclarecido" Paquier; los gramáticos medianistas estudiaban a Antonio de Nebrija y traducían en la mañana a Virgilio y por la tarde a Cicerón. Los minimistas estudiaban al mismo autor, pero traducían las fábulas de Fedro. El número total de alumnos era de 96, de los cuales 20 eran minimistas, 53 medianistas, 21 filósofos y 3 teólogos. ${ }^{23}$ También le enviaba la relación de egresos e ingresos propios del Colegio, así como el monto del déficit a cubrir por la administración estatal y el cual ascendía a 62 pesos y 3 reales." 24 (AHQ, Fondo Ejecutivo, 1835, 20 de enero).

Iniciaba el año de 1836, y, los jóvenes queretanos que habían cursado en los Nacionales Colegios las cátedras de gramática necesarias para continuar con estudios superiores, no tenían más opción que el estudio de Filosofía; la cátedra de Teología Moral, con sólo tres alumnos, parecía estar a punto de extinguirse. En consecuencia, el rector advertía al gobernador Rafael Canalizo que los jóvenes abandonaban los estudios o se trasladan a otras ciudades por no existir en el Colegio estudios mayores. Para remediar lo anterior, Ochoa solicitó al gobernador que se habilitaran las cátedras de Teología Escolástica y la Derecho Civil y Canónico, estas últimas con base en el decreto del 4 de octubre de 1827.

Para enero de 1837 el cambio de régimen obligó a los Colegios a jurar el nuevo ordenamiento legal expedido en 1836 conocido como Siete Leyes, el cual sustituyó a la Constitución de 1824. Entre los asistentes a dicho acto figuraba al licenciado Ignacio Villaseñor como catedrático de Jurisprudencia. Los reclamos del rector habían sido escuchados, al menos parcialmente. $^{25}$

Para entonces, la administración estatal ya tenía pleno control de la vida interna de los Colegios. El gobernador poseía la facultad de nombrar al rector y a los catedráticos, aprobar los textos que debían leerse, decidir la apertura o no de nuevas cátedras, opinar sobre las normas disciplinarias, disponer de sus ingresos... y también de sus espacios.

Fue así como a partir del interés por establecer una escuela de primeras letras, el gobernador Ramón Covarrubias (diciembre 1829 - junio 1830 y abril de 1837- noviembre 1840) ordenó a principios de 1839 que se dispusiera del espacio donde se había ubicado la escuela gratuita en el antiguo Colegio de San Ignacio. El gobernador no imaginó que dicha disposición iba a desatar un conflicto con la parroquia por la ocupación de espacios que pertenecían a

\footnotetext{
${ }^{23} \mathrm{AHQ}$, Fondo Ejecutivo 1834, caja 7, "Estado que manifiesta del número de alumnos del Colegio de San Francisco Javier, las cátedras que cura, y autores que en ellas estudian", sin fecha.

${ }^{24} \mathrm{AHQ}$, Fondo Ejecutivo 1834, caja 7, "Presupuesto de los sueldos vencidos al día 20 del presente mes en el Colegio de San Francisco Javier y de los gastos ordinarios erogados en el mismo", Querétaro, 20 de marzo de 1835.

${ }^{25}$ Universidad Autónoma de Nuevo León, Fondo Fernando Díaz Ramírez, en adelante UANL/FFDR, "Libro de determinaciones y acuerdos de este Real Colegio de San Francisco Xavier y Reales estudios de San Ignacio (1778-1839), Colección Digital de la UANL.
} 
los Colegios. ${ }^{26}$ Para sorpresa de las autoridades civiles, el cura párroco, Miguel Zurita, se negó a acatar la instrucción del gobernador, por lo que el nuevo titular del Ejecutivo, José Francisco Figueroa (diciembre 1840- noviembre 1841), solicitó al rector lo informara sobre el particular. Ochoa le hizo llegar los documentos probatorios del derecho de propiedad que tenía el Colegio sobre la casa cural, señalando que los límites con la parroquia habían sido claramente definidos desde finales del siglo XVIII. Así, aseguraba:

[...] la habitación del señor cura de la parroquia de Santiago asignada [...] por el Rey, no comprende más que un tránsito del Colegio de San Ignacio, que corre de oriente a poniente y se [comunica] por la escalera de la sacristía; tapados dos arcos uno del claustro que va de ésta a la principal y al coro, y otro frente a la escalera del anterefectorio, en que hoy están los comunes de la casa cural. En este recinto se encuentran nueve aposentos, señalados por aquel funcionario para vivienda del señor cura [...]

Y añadía: "Estos límites tan bien prefijados en el expediente de la materia, que no pudieron traspasarse sino por la violencia y el despojo, sólo puedo decirle: que el señor Zurita continuó en la posesión de sus antecesores, por orden del Sr. Canalizo gobernador del departamento que se la concedió graciosamente [...]". ${ }^{27}$

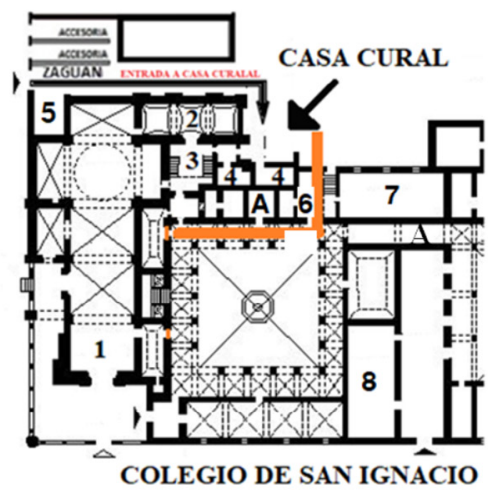
1. TEMPLO
2. SACRISTÍA
3. ANTESACRSITÍA
4. ANEXOS
5. ENTRADAA CASA CURAL
6. ANTE REFECTORIO
7. REFECTORIO
8. ESCUELA DE PRIMERAS
LETRAS
A. 5 APOSENTOS

PLANTA BAJA

Figura 1 División entre la casa cural y el Colegio.

Fuente: Catálogo Nacional de Monumentos Históricos Inmuebles del Estado de Querétaro, CD 1. (2003), Conaculta-INAH, México. Plano intervenido por Fernando Saavedra..

\footnotetext{
${ }^{26} \mathrm{AHQ}$, Fondo Ejecutivo 1839, caja 8, informe del rector Manuel de Ochoa al gobernador Ramón Covarrubias, Querétaro, 9 de enero de 1839.

${ }^{27} \mathrm{AHQ}$, Fondo Ejecutivo 1840, caja 4, informe del rector Manuel de Ochoa al gobernador Francisco Figueroa, Querétaro, 30 de diciembre de 1840 .
} 


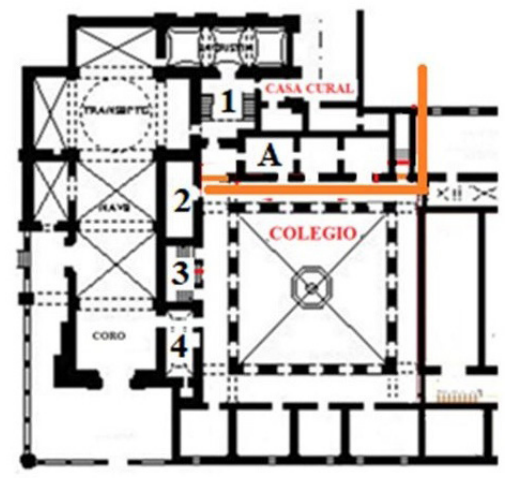

1. ESCALERADE SACRISTÍA

2. ANTESALA DE TRIBUNA

3. ESCALERA PRINCIPAL DEL COLEGIO

4. ANTECORO

A. 4 APOSENTOS

Figura 2 División entre la casa cural y el Colegio.

Fuente: Catálogo Nacional de Monumentos Históricos Inmuebles del Estado de Querétaro, CD 1. (2003), Conaculta-INAH, México. Plano intervenido por Fernando Saavedra.

El asunto de los límites con la parroquia no se resolvió y ante la insistencia del gobernador Figueroa, en enero de 1841 el rector Ochoa informaba que el cura párroco se negaba a exponer sus argumentos por escrito y advertía que continuaría en posesión de los espacios así tuviera que acudir ante un juez. ${ }^{28}$

\section{Aumentan las medidas de control}

Manuel de Ochoa presentó su renuncia al gobernador cuando apenas habían trascurrido los primeros días del año de $1841 .{ }^{29}$ Acto seguido, solicitó se le entregara un cáliz del Colegio a cuenta del adeudo que con él se tenía por concepto de sueldos atrasados. ${ }^{30}$ Tras ser aceptada su renuncia, se le ordenó entregar la estafeta al catedrático de Derecho, el licenciado José Ignacio Villaseñor y Cervantes. Al frente de los Colegios se encontraba por vez primera un laico. ${ }^{31}$

Si bien avanzaba el control del Estado sobre sus activos, entre los que se encontraba la renta de la huerta, ${ }^{32}$ ni los recursos propios ni el monto aportado por la administración pública

${ }^{28} \mathrm{AHQ}$, Fondo Ejecutivo 1841, caja 12, informe del rector Manuel de Ochoa al gobernador José Francisco Figueroa, Querétaro, 25 de enero de 1841.

${ }^{29} \mathrm{AHQ}$, Fondo Ejecutivo 1841, caja 12, carta de Manuel de Ochoa al gobernador José Francisco Figueroa, Querétaro, 29 de enero de 1841

${ }^{30} \mathrm{AHQ}$, Fondo Ejecutivo 1841, caja 6, solicitud de Manuel de Ochoa al gobernador José Francisco Figueroa, Querétaro, 25 de mayo de 1841.

${ }^{31} \mathrm{AHQ}$, Fondo Ejecutivo 1841, caja 8, nota al rector Manuel de Ochoa, Querétaro, 29 de enero de 1841

${ }^{32} \mathrm{AHQ}$, Fondo Ejecutivo 1839, caja 9, carta del rector Manuel de Ochoa al gobernador Ramón Covarrubias, Querétaro,

13 de marzo de 1839 y nota del gobernador al rector, Querétaro, 14 de marzo de 1839. 
eran suficientes para sostener con dignidad a los Colegios y pagar con puntualidad a los catedráticos. Con el propósito de evitar que la decadencia del Colegio llegase al extremo, el gobernador tomó algunas medidas con el fin de darle un "mediano arreglo". Consideraba que los miembros de la Junta del Colegio no eran las personas más a propósito y estimaba que ésta debería estar integrada por catedráticos. ${ }^{33}$ Fue así como a iniciativa del Ejecutivo, la Junta Departamental expidió un decreto publicado el 18 de noviembre de 1841 y el cual establecía que la anterior se compondría del rector, los catedráticos y el maestro de aposentos. La administración de los recursos del Colegio sería inherente al cargo de rector sin derecho a gratificación, mientras que el producto de sus rentas se distribuiría entre sus empleados "[...] dando de toda cuenta al Gobierno del departamento en el mismo mes". También disponía que la Junta inspeccionaría la recaudación de los fondos que pertenecían al Colegio, la inversión de los mismos, la organización de la enseñanza según las leyes y el estado general de la institución. ${ }^{34}$

Un mes más tarde, el gobernador insistía en que el rector señalara con precisión qué piezas, patios y corredores del Colegio de San Ignacio pertenecían al curato y por qué razón. ${ }^{35}$ El conflicto con la parroquia estaba aún lejos de solucionarse.

\section{La reforma educativa de Manuel Baranda y los Nacionales Colegios}

En el año de 1843 se formó una comisión encabezada por el ministro Manuel Baranda y un nuevo Plan de Instrucción Pública se dio a conocer el 18 de agosto de ese año con obligatoriedad para todos los departamentos. (Ríos, 214: 11). Entre otras cosas, se ordenaba que los colegios se ajustaran al modelo de los colegios de la capital y en sus bases generales estipulaba como estudios preparatorios para las carreras de Foro (Derecho), Ciencias Eclesiásticas y Medicina, las materias siguientes: gramática castellana, gramática latina, francesa e inglesa; ideología, lógica, metafísica, y moral; matemáticas elementales, física elemental, cosmografía, geografía, cronología; economía política, dibujo elemental y lineal.

La carrera de Derecho incluiría las siguientes cátedras: derecho natural y de gentes, derecho político y principios de legislación, elementos de derecho romano, derecho civil y criminal, derecho canónico y prácticas. Para la carrera eclesiástica: historia eclesiástica, sagrada escritura, teología, estudio de los padres y disciplina eclesiástica. (Ríos: 2014, 28) Los grados que se concedían eran los de bachiller, licenciado y doctor. (Ríos, 2014: 30).

\footnotetext{
${ }^{33} \mathrm{AHQ}$, Fondo Ejecutivo 1841, caja 9, Junta Departamental año de 1841, Querétaro, 29 de octubre de 1841.

${ }^{34} \mathrm{AHQ}$, Fondo Ejecutivo 1841, caja 12, decreto de la Junta Departamental de Querétaro relativo a la conformación y atribuciones de la Junta del Colegio, Querétaro, 18 de noviembre de 1841.

${ }^{35} \mathrm{AHQ}$, Fondo Ejecutivo 1841, caja 6, nota del gobernador al rector, Querétaro, 28 de diciembre de 1841.
} 
En términos generales, se pretendía uniformar la educación definiendo las materias que debían cursarse en los estudios preparatorios y superiores, además de establecer una serie de normas relacionadas con los exámenes y la obtención de grados y títulos. Los anteriores serían otorgados por cada establecimiento educativo, pero deberían ser validados por la Junta Directiva General de Estudios de la capital del país.

Por otra parte, el Plan subrayaba la necesidad de que los alumnos recibieran "sólidos principios religiosos" y disponía que los textos para cada una de las materias serían los que el Gobierno central determinara. Asimismo, la reforma planteaba la creación de una Junta General de Estudios con sub dependencias en cada uno de los departamentos. En Querétaro, una junta respectiva estuvo a cargo del doctor José Miguel Zurita. ${ }^{36}$

En síntesis, el plan de 1843 intentaba solventar tres cuestiones que habían preocupado
por dos décadas al Estado mexicano, la primera era la creación de un fondo para
financiar la instrucción pública [Fondo General de Instrucción Pública]; la segunda, la
erección de un órgano rector que se hiciera cargo de todos los asuntos concernientes
a los establecimientos y, por último, la unificación de los planes de estudios y de las
normas que regían a los centros de enseñanza en todo el territorio. (Hidalgo, 2013: 7).

Al tiempo que se expedía la reforma, en agosto de 1843 Manuel Baranda pidió información a todos los departamentos con el propósito de realizar una evaluación de la educación pública del país. Los resultados de este informe quedaron plasmados en la Memoria del Ministerio de Justicia e Instrucción Pública Presentada ante el Congreso General en 1845, y en la cual aparecían los reportes de varios establecimientos educativos. Sin embargo, la única referencia relativa a el departamento de Querétaro, correspondía al número de alumnos que cursaron el año escolar de 1843 en el Convento de franciscanos de Michoacán y en el Colegio de San Ignacio y se San Francisco Javier, para el cual se reportaban 12 alumnos internos y 245 externos, es decir, un total de 257 estudiantes. (Ríos y Rosas, 2015: 307).

Siendo que contenidos y métodos de la educación media y media superior dependían de las decisiones del gobierno central, por instrucciones del ministro Baranda al gobernador Sabás Antonio Domínguez, ${ }^{37}$ se suprimió la cátedra de Teología Moral en los Colegios de San Fernando y San Francisco Javier sustituyéndola por la de Teología Escolástica. ${ }^{38}$ Sin embargo, no había transcurrido ni un mes cuando un decreto de la junta departamental restableció la clase de Teología Moral, enseñándose por la obra de Ligorio mientras el supremo gobierno

\footnotetext{
${ }^{36} \mathrm{AHQ}$, Fondo Ejecutivo 1846, caja 3, carta de José Miguel Zurita al gobernador Francisco Berdusco, Querétaro, 6 de noviembre de 1846 .

37 Sabás Antonio Domínguez gobernó del 30 de noviembre al 18 de diciembre de 1840, del $1^{\circ}$ de noviembre de 1841 al $1^{\circ}$ de febrero de 1842, del 15 de mayo al 24 de noviembre de 18443 y del 22 de diciembre de 1844 al 30 de abril de 1846.

${ }^{38} \mathrm{AHQ}$, Fondo Ejecutivo 1843, caja 1, Junta departamental de Querétaro, Querétaro, 02 de octubre de 1843.
} 
señalaba la que considerara conveniente. ${ }^{39}$ Por otra parte, el ministro Baranda en atención a la recomendación del gobernador, nombraba al bachiller Luis Zelaá como catedrático de Teología del Colegio. Así mismo, se reconocía como propietario de la plaza de rector del Colegio de San Ignacio y San Francisco Javier, al licenciado Ignacio Villaseñor. ${ }^{40}$

La subordinación al centro no debía ser puesta en duda y los Colegios eran a partir de entonces considerados oficialmente como "Nacionales". En consecuencia, Baranda envió una circular a los gobernadores informando que una vez establecidas las juntas subdirectoras de estudios en los departamentos en que existen colegios nacionales, éstas debían ser el conducto de comunicación entre los colegios y demás autoridades relacionadas con la instrucción secundaria. ${ }^{41}$

La reforma trató de aplicarse en cada departamento, pero en cada uno registró ritmos y características propias. En el de Querétaro, al menos en lo que correspondía a los Colegios, las cosas parecían no haber cambiado mucho y la falta de recursos se había vuelto crónica. Pese a las instrucciones giradas por el gobernador Domínguez a la Tesorería Departamental, el presupuesto con que se contaba no permitía suministrar la Colegio los recursos ofrecidos. ${ }^{42}$

En agosto de 1846 la República recobró su carácter federal por lo que se advertía al rector de los Colegios: "Estando restablecida la soberanía de los Estados, son absolutamente independientes de la Junta Directiva de Estados los Colegios de esta capital por consiguiente no obedecerá $[. .$.$] orden alguna que no emane del Gobierno del Estado [...]. { }^{43}$

\section{La primera gran crisis}

Los años de 1846 y 1847 fueron en extremo difíciles para el país y para los Colegios. Los rectores no duraban más que unos cuantos meses en el puesto; por periodos cortos y en más de una ocasión, obtuvieron el cargo los licenciados José Ignacio Villaseñor, José María Ochoa y Jesús María Vázquez.

A finales del mes de agosto de 1847, un miembro de las familias más acaudaladas de Querétaro tomó posesión del Gobierno: se trataba de Francisco de Paula Mesa. Al estar ocupada la Ciudad de México por fuerzas de los Estados Unidos, el gobernador ofreció que en la ciudad capital se establecieran los poderes federales. Mientras tanto, la situación económica del país, de los estados y naturalmente de los Colegios, se tornaba cada vez más

\footnotetext{
${ }^{39} \mathrm{AHQ}$, Fondo Ejecutivo 1843, caja 1, Secretaría de la Junta Departamental, Querétaro, 26 de octubre de 1843.

${ }^{40} \mathrm{AHQ}$, Fondo Ejecutivo 1843, caja 2, Ministerio de Justicia e Instrucción Pública, Querétaro, 14 de diciembre de 1843.

${ }^{41} \mathrm{AHQ}$, Fondo Ejecutivo 1843, caja 8, circular del Ministerio de Justicia e Instrucción Pública, Querétaro, 30 de octubre de 1844.

$42 \mathrm{AHQ}$, Fondo Ejecutivo 1845, caja 1, instrucciones del gobernador Sabas Antonio Domínguez al tesorero departamental, Querétaro, enero 29 de 1845 y respuesta del tesorero, sin fecha.

${ }^{43} \mathrm{AHQ}$, Fondo Ejecutivo 1846, caja 5, instrucción del Cobierno del Estado al rector de los Colegios, Querétaro, 7 de octubre de 1846.
} 
difícil. De la oficina del gobernador se enviaba al rector la siguiente nota: "Las sumas escaseces en que se halla la tesorería del Estado, no le han permitido dar a los empleados ni una pequeña parte de los sueldos que vencieron en el mes de abril último, por este motivo no me es posible expedir el libramiento de ochenta pesos que usted indica le faltan para completar los gastos de ese establecimiento". ${ }^{44}$

La presión del Gobierno sobre la administración de los Colegios aumentó y de no muy buen modo se pidió al rector el "[...] estado circunstanciado de las fincas urbanas de esos Colegios, especificando las que están ocupadas, renta que paguen los inquilinos, cuáles están vacías, cuáles no producen renta y por qué causa [...]”. ${ }^{45}$ También se le exigió el documento que acreditara la propiedad de la casa cural ${ }^{46}$ y la noticia del paradero de una lámpara de plata que se había reportado como desaparecida. ${ }^{47}$ Finalmente, se le instó a evitar que los empleados del Colegio no cumplieran con los deberes para los que se les había contratado. 48 El rector Luis Zelaá optó por la renuncia; para finales de año ya se les debían cinco meses a los catedráticos. ${ }^{49}$

Los Colegios parecían ser una piedra en el zapato para el Gobierno estatal. Quien había sido titular del Ejecutivo, Francisco Berdusco (septiembre de 1846-agosto de 1847), dejaba asentado:

No me encuentro satisfecho [...] habiendo visitado en los últimos días el establecimiento, vi con pena que sus rentas no se habían distribuido con orden ni economía, ni llevándose antes de mi gobierno cuentas formales de ingresos ni egresos, y que estaban en un completo abandono la librería, el tesoro y el archivo. La primera sin aseo ni limpieza ha sido destruida por la humedad y los insectos, hasta quedar reducida a unos cuántos libros truncos; en el segundo se echa de menos la única alhaja que existía [se refería a la lámpara...] En el último faltan las escrituras que comprueban que, en el ramo de minería, consulado y otros, reconocen a dicho establecimiento muchos miles de pesos [...]..$^{50}$

\footnotetext{
${ }^{44} \mathrm{AHQ}$, Fondo Ejecutivo 1847, caja 7, nota al rector del Colegio, Querétaro, 27 de mayo de 1847.

${ }^{45} \mathrm{AHQ}$, Fondo Ejecutivo 1847, caja 13, nota del gobernador Francisco Berdusco al rector, Querétaro, 21 de julio de 1847.

${ }^{46} \mathrm{AHQ}$, Fondo Ejecutivo 1847, caja 13, nota del gobernador Francisco Berdusco al rector, Querétaro, 13 de julio de 1847.

${ }^{47} \mathrm{AHQ}$, Fondo Ejecutivo 1847, caja 13, nota del gobernador Francisco Berdusco al rector, Querétaro, 2 de agosto de 1847.

${ }^{48} \mathrm{AHQ}$, Fondo Ejecutivo 1847, caja 13, nota del gobernador Francisco de Paula Mesa al rector, Querétaro, 13 de diciembre de 1847.

${ }^{49} \mathrm{AHQ}$, Fondo Ejecutivo 1848, caja 5, nota del gobernador Francisco de Paula Mesa, 23 de noviembre de 1848.

${ }^{50}$ El Federalista, núm. 136, abril 14 de 1849, 3. Hacia finales del siglo XVIII varias corporaciones eclesiásticas habían depositado parte de sus caudales en el Consulado de México, tal era en caso de Colegio de San Francisco Javier de Querétaro. Véase Guillermina Del Valle, "Las corporaciones religiosas en los empréstitos negociados por el consulado de México a fines del siglo XVIII", en Iglesia, Estado y Economía. Siglos XVI al XIX, coord. por María del Pilar Martínez (México: Instituto Mora /UNAM, 1995), 225-239.
} 
Los redactores de El Federalista sugerían investigar si los fondos con que contaba el Colegio eran suficientes para su mantenimiento; de no ser así, el Congreso tendría la obligación de destinarle los recursos suficientes para cubrir el déficit. Resultaba además indispensable diseñar un nuevo plan de estudios y tomar medidas severas "para reprimir la insolencia de algunos jóvenes". En su opinión, la falta de disciplina era tan grave "[...] que por eso muchos padres de familia no quieren poner a sus hijos en el estudio, porque temen, y no sin fundamento, que se perviertan con el trato de tan peligrosos compañeros; por eso también cada día va siendo más reducido el número de alumnos [...los cuales] apenas llega a ciento". ${ }^{1 .}$

\section{El retorno de los jesuitas como respuesta a la crisis}

Al término de la guerra de intervención, en 1849, se presentaron nuevas solicitudes acerca de permitir el retorno de los jesuitas, expulsados del territorio por segunda ocasión en 1821. Fue entonces cuando los congresistas queretanos resolvieron enviar al gobernador, a fin de que procediera a su publicación, el decreto por el cual se restablecía la Compañía de Jesús y se le hacía entrega de los Colegios para que "los dirija y administre conforme a sus reglas". 52

Sin embargo, el gobernador se negó a publicar el tan polémico decreto, bajo los argumentos de que era políticamente inconveniente y legalmente improcedente, ya que el retorno de la orden al país era un asunto que le competía exclusivamente al Gobierno central. Finalmente, el decreto no fue publicado pero el conflicto obligó a De Paula a renunciar al cargo. Lo sucedió Juan Manuel Fernández de Jáuregui (diciembre de 1849- marzo de 1850).

El 6 de diciembre de 1849 un nuevo decreto terminó con cualquier idea de cambio y reafirmó la autoridad del Gobierno sobre los Colegios: "Se faculta al Cobierno para que dicte las providencias que juzgue necesarias a fin de que se arreglar provisionalmente el Colegio y comience sus tareas ordinarias en enero del año entrante". ${ }^{53}$ Otro más, de fecha 2 de enero de 1850, anunciaba: "El gobierno tomará de los fondos de instrucción pública, la cantidad de 425 pesos para hacer los reparos de que tienen necesidad los Colegios de San Ignacio y San Francisco Javier de esta ciudad [...]". ${ }^{54}$

Así, tras el episodio jesuita, el gobierno se preparó para sacar el Colegio del abismo. Varias medidas fueros dictadas a fin de mejorar su situación; por ejemplo, se estipuló que las licencias otorgadas al rector, catedráticos y demás empleados del Colegio, fueran sin goce

\footnotetext{
${ }^{51}$ El Federalista, núm. 4, agosto 19 de 1849, 6-7.

${ }^{52} \mathrm{AHQ}$, Fondo Ejecutivo 1849, caja 5, decreto del Congresos del Estado, Querétaro, 18 de diciembre de 1849.

${ }^{53}$ UANL/FFDR, "Colección de decretos del Congreso del Estado de Querétaro desde agosto de 1849, hasta igual mes de 1851", Colección Digital de la UANL, 15.

${ }^{54}$ UANL/FFDR, "Colección de decretos del Congreso del Estado de Querétaro desde agosto de 1849, hasta igual mes de 1851", Colección Digital de la UANL, 17.
} 
de sueldo. ${ }^{55}$ Pero las medidas resultaron insuficientes y la situación en los Colegios no mejoró. Los editores de El Federalista hicieron un llamado al rector para evitar que los alumnos faltaran tanto a clases, ${ }^{56}$ mientras que, por otra parte, continuaban las quejas con motivo de la indisciplina de los estudiantes al grado de referirse a ellos como: "soeces colegiales, que más parecen presidiarios". ${ }^{57}$

Faltando pocos años para la rebelión de Ayutla y el triunfo del proyecto liberal, el cual daría pasos definitivos en materia de secularización y terminaría por limitar la injerencia de la Iglesia en el ámbito educativo, los Colegios de San Ignacio y San Francisco Javier atravesaban por una profunda crisis y estaban a muy poco de perder todo resto de autonomía, para convertirse finalmente en Colegio Civil del Estado el año de 1870.

\section{Reflexiones Finales}

En términos generales, resulta impostergable la construcción de un recuento histórico de los Colegios de San Ignacio y San Francisco Javier, a la luz de nuevas fuentes y en el marco de recientes aportaciones teórico metodológicas. La presente investigación, no sólo nos permite ofrecer un panorama de la primera mitad del siglo XIX, ignorada por la historiografía local, sino que posibilita una concatenación coherente de los acontecimientos a la luz de la secularización educativa promovida por autoridades nacionales y estatales. En el caso de Querétaro, a pesar de la fuerte presencia de la Iglesia Católica, el Gobierno local se esmeró por hacer de la educación una cuestión de Estado, sin que lo anterior significara poner en entredicho la tradición católica ni en respeto a las autoridades eclesiásticas. Es así como la secularización que se registró en el ámbito de las Colegios tuvo una triple vertiente: como supremacía del Estado en el ámbito de la educación pública, como implementación de un discurso científico y como eliminación paulatina del componente teológico.

Al cabo de unos cuantos años, en el caso particular de los antiguos Colegios jesuitas, no sólo el contenido, también el continente, pasó a la esfera de lo público. El conflicto por los límites entre la parroquia y el Colegio, ejemplificaron en el terreno de los hechos una ruptura con el viejo orden. Sería hasta finales del siglo XIX cuando un documento notarial los estableció con toda precisión, levantándose los muros que separaban, sin lugar a dudas, los ámbitos de lo sagrado y lo profano.

\footnotetext{
${ }^{55} \mathrm{AHQ}$, Fondo Ejecutivo 1850, caja 2, comunicación del gobernador José Antonio Urrutia al rector, Querétaro, 15 de marzo de 1850.

${ }^{56}$ El Federalista, núm. 64, junio 27 de 1852, 3-4.

${ }^{57}$ El Federalista, núm. 77, septiembre 26 de 1852, 1-2
} 


\section{Archivos}

AHQ. Archivo Histórico del Estado de Querétaro, Fondo Ejecutivo.

BC. Biblioteca del Congreso del Estado de Querétaro. Fondo Manuel Septién y Septién.

Universidad Autónoma de Nuevo León, Fondo Díaz Ramírez, Colección Digital de la UANL.

\section{Referencias hemerográficas}

Periódico El Federalista, Querétaro.

\section{Referencias bibliográficas}

Arreola, Álvaro (2006), Patio Barroco 400 años en la educación cuatro décadas en la UAQ, Universidad Autónoma de Querétaro, Querétaro.

Díaz, Fernando (1971), Historia de la Universidad de Querétaro, parte primera, Ediciones del Cobierno del Estado, Querétaro.

Congreso del Estado de Querétaro (1828), Proyecto de Ley sobre Instrucción Pública. Presentado al H. Congreso del Estado de Querétaro en 18 de diciembre de 1827 por la Comisión respectiva, Imprenta de Rafael Escandón, Querétaro.

Dublán, Manuel y José María Lozano (1876), Legislación mexicana o colección completa de las disposiciones legislativas expedidas desde la independencia de la República, Tomo 2, Imprenta del Comercio, México.

García, Marta Eugenia (2010), "Liberalismo y Secularización: impacto de la primera reforma liberal", en Patricia Galeana (coord.), Secularización del Estado y la sociedad, Siglo XXI editores, México, pp. 61-90.

García, Marta Eugenia (2011) "Tradición y modernidad en Querétaro" en Ramón del Llano y Oliva Solís (coords.), Tradición y modernidad en el estado Querétaro (siglos XIX-XX), UAO/Miguel Ángel Porrúa, México, pp.21-46.

Landa, Cecilia (2014), Historia de la Facultad de Ingeniería. Universidad Autónoma de Querétaro, Universidad Autónoma de Querétaro, México.

Medina, Luis (1972), "El Colegio de San Ignacio y el Seminario de San Javier en Querétaro (1625-1767)", en Manuel Pérez (ed.), La compañía de Jesús en México. Cuatro siglos de labor cultural (1572-1972), Editorial Jus, México.

Obregón, Alejandro, Gabriel Rincón y José Anaya (1993), Historia de la Universidad Autónoma de Querétaro, Tomo 1, Universidad Autónoma de Querétaro, México.

O’Neill, Charles (2001), Diccionario histórico de la Compañía de Jesús, Universidad Pontifica Comillas, España.

Ríos, Rosalina y Cristian Rosas (2011), La Reforma Educativa de Manuel Baranda. Documentos para su estudio (1824-1846), Universidad Nacional Autónoma de México, México.

Urquiola José (2017), La fundación y los bienes del colegio de San Ignacio Querétaro. Querétaro, Miguel Ferro Editio, Querétaro. 


\section{Referencias electrónicas}

Arredondo, María (2006), "Políticas públicas y educación secundaria en la primera mitad del siglo XIX en México" en Revista mexicana de investigación educativa, núm. 32, enero-febrero, pp. 37-62, disponible en: https://biblat.unam.mx/es/revista/revista-mexicana-de-investigacion-educativa/ articulo/politicas-publicas-y-educacion-secundaria-en-la-primera-mitad-del-siglo-xix-enmexico (fecha de consulta: 23/1/2020).

Arredondo, Adelina y Roberto González (2014), "De la secularización a la laicidad educativa en México" en Historia de la educación, vol. 15, núm.2, pp.140-167, disponible en http://ppct.caicyt.gov.ar/index. php/anuario/article/view/2968, (fecha de consulta: 4/04/2019).

Díaz, Clementina (1974), "El Colegio Máximo de San Pedro y San Pablo. Cuarto Centenario" en Revista de la Universidad Autónoma de México, núm.2, octubre, pp.30-36, disponible en https://www.revistadelauniversidad.mx/download/f498d0a5-d5c7-404e-9557-6bbd7504ae0d?filename=el-colegiomaximo-de-san-pedro-y-san-pablo-cuarto-centenario, (fecha de consulta: 4/02/2019).

Hidalgo, Mónica (2002), "Reseñas. Rosalina Ríos Zúñiga, La educación de la Colonia a la República. El Colegio de San Luis Gonzaga y el Instituto Literario de Zacatecas" en Estudios de historia novohispana, núm. 27, pp.253-266, julio-diciembre, disponible en: http://www.historicas.unam.mx/publicaciones/revistas/novohispana/pdf/novo27/0389.pdf, (fecha de consulta: 15/01/2020).

Hidalgo, Mónica (2013), "La Reforma de 1843 y los reglamentos del Nacional Colegio de San Ildefonso" en Revista Iberoamericana de Educación Superior, núm.10, vol.4, pp. 56-73, disponible en: https:// www.sciencedirect.com/science/article/pii/S2007287213719243, (fecha de consulta: 7/01/2020).

Ríos, Rosalina (2014), "Secularización, centralización y configuración de un sistema de instrucción pública en México, primera mitad del siglo XIX (1812-1854)", Seminario de Historia de la Universidad Nacional, disponible en: https://seminariohistoriauniversidadl.files.wordpress.com/2014/02/rosalina-rc3ados-zc3bac3bliga-secularizacic3b3n-centralizacic3b3n-y-configuracic3b3n-de-un-sistema-de-instruccic3b3n-pc3bablica-en-mc3a9xico-primera-mitad-del-siglo-xix-1812-1854.pdf, (fecha de consulta: 6 /11/2019). 